\title{
THE ETIOLOGIC RELEVANCE OF 3-D PATHOANATOMY OF ADOLESCENT IDIOPATHIC SCOLIOSIS
}

\author{
RELEVÂNCIA ETIOLÓGICA DA ANATOMOPATOLOGIA TRIDIMENSIONAL DA ESCOLIOSE \\ IDIOPÁTICA DO ADOLESCENTE
}

\author{
RELEVANCIA ETIOLÓGICA DE LA ANATOMOPATOLOGÍA TRIDIMENSIONAL DE LA \\ ESCOLIOSIS IDIOPÁTICA DEL ADOLESCENTE
}

Tom Schlösser ${ }^{1}$, Rob Brink ${ }^{1}$, René Castelein ${ }^{1}$

1. University Medical Center Utrecht, Department of Orthopedic Surgery, Utrecht, the Netherlands.

\begin{abstract}
Despite many years of dedicated research into the etiopathogenesis of adolescent idiopathic scoliosis, there is still no single distinct cause for this puzzling condition. In this overview, we attempt to link knowledge on the complex three-dimensional pathoanatomy of AIS, based on our ongoing research in this field, with etiopathogenic questions. Evidence from multiple recent cross-sectional imaging studies is provided that supports the hypothesis that AIS has an intrinsic biomechanical basis: an imbalance between the biomechanical loading of the upright human spine due to its unique sagittal configuration on the one hand, and the body's compensating mechanisms on the other. The question that remains in the etiology of AIS, and the focus of our ongoing research, is to determine what causes or induces this imbalance.

Keywords: Scoliosis; Etiology; Pathogenesis; Research.

\section{RESUMO}

Apesar dos muitos anos de pesquisa dedicada à etiopatogenia da escoliose idiopática do adolescente, ainda não existe uma única causa distinta para essa afecção intrigante. Nesta visão geral, tentamos fazer a ligação do conhecimento sobre a complexa anatomia patológica tridimensional da EIA, com base em nossas pesquisas em andamento nessa área, com as questões da etiopatogenia da doença. As evidências dos diversos estudos transversais recentes são apresentadas e corroboram a hipótese de que a EIA tem base biomecânica intrínseca: o desequilíbrio entre a carga biomecânica devido à sua configuração sagital única por um lado, e os mecanismos compensatórios do corpo, por outro. Ainda há dúvidas sobre a etiologia da ElA e o foco de nossa pesquisa em andamento é determinar o que causa ou induz esse desequilíbrio.
\end{abstract}

Descritores: Escoliose; Etiologia; Patogênese; Pesquisa.

\section{RESUMEN}

A pesar de los muchos años de investigación dedicada a la etiopatogenia de la escoliosis idiopática del adolescente, aún no existe una única causa distinta para esa afección intrigante. En esta visión general, tratamos de hacer la conexión del conocimiento sobre la compleja anatomía patológica tridimensional de la EIA, con base en nuestras investigaciones en marcha en esa área, con las cuestiones de la etiopatogenia de la enfermedad. Las evidencias de los diversos estudios transversales recientes son presentadas y corroboran la hipótesis de que la EIA tiene base biomecánica intrínseca: el desequilibrio entre la carga biomecánica debido a su configuración sagital única por un lado, y los mecanismos compensatorios del cuerpo, por otro. Aún hay dudas sobre la etiología de la ElA y el enfoque de nuestra investigación en marcha es determinar lo que causa o induce ese desequilibrio.

Descriptores: Escoliosis; Etiología; Patogénesis; Investigación.

\section{INTRODUCTION}

Scoliosis is a three-dimensional (3-D) deformity of the spine and trunk that primarily affects previously healthy children. It is a classic orthopedic disorder. ${ }^{1}$ The most common type of scoliosis is idiopathic scoliosis. The term 'idiopathic' (from the Greek: í $\delta$ ıs $=$ one's own and $\pi \alpha \dot{\theta} \theta \mathrm{o} \varsigma=$ suffering) indicates that the disease is not linked to any physical impairment or previous medical history. Despite many years of dedicated research into the etiopathogenesis of idiopathic scoliosis, there is no single, distinct cause for this condition, and a number of intriguing questions remain. ${ }^{2,3}$ The purpose of this study is to provide, based on our ongoing research into the etiopathogenesis of idiopathic scoliosis, answers to some of these questions, namely:

1. Why is scoliosis a disease of man?

2. Why are thoracic curves predominantly right convex in adolescents, but left convex in infants?

3. What is the role of relative anterior spinal overgrowth (RASO)?

Why is scoliosis a disease of man?

Idiopathic scoliosis appears to occur exclusively in humans, and it has not been observed in any other mammals. ${ }^{4}$ Other spinal

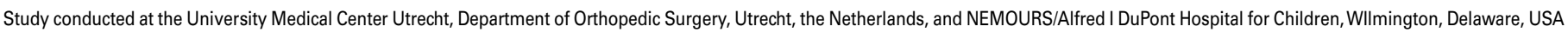
and Prince of Wales Hospital, Chinese University of Hong Kong, Shatin, Hong Kong, China.

Correspondence: René Castelein. Department of Orthopedic Surgery, G05.228, University Medical Center Utrecht, P.O. Box 85500, 3508 GA Utrecht, The Netherlands. r.m.castelein@ umcutrecht.nl. 
deformities have been observed or created in animals, but they either have iatrogenic, post-traumatic, neuromuscular or congenital etiologies. Why is this?

The essential difference between man and all other vertebrates is not any major difference in spinal architecture, since this is relatively uniform throughout all species, with broad vertebral endplates and discs to withstand axial loading, and posteriorly located synovial joints and protuberances for muscle and ligament attachment to withstand anteriorly directed shear loads. Nor is it the fact that man is bipedal; there have always been many bipedal species, starting with most dinosaurs. Human posture and locomotion, however, is different from all other vertebrates, quadrupedal and bipedal alike, in two aspects: 1. The uniquely human pelvic lordosis, also known as a lordotic angulation between the ischial and iliac bones, ${ }^{5-8}$ and

2. The ability to simultaneously extend both hips and knees. ${ }^{9}$

Man, unlike any other species, actually has three well developed lordoses along the spine, at least after infancy: one between the iliac and ischial bones, one in the lumbar region, and one in the cervical region. It is generally accepted by anthropologists that habitual human bipedalism and sagittal spinopelvic alignment can be attributed to morphological changes in the pelvis during human evolution. ${ }^{5,10}$ In the earliest hominid specimen to date, an Australopithecus afarensis that was found in Ethiopia (also known as 'Lucy'), as well as in other hominids, anthropologists observed that angulation of the ilium relative to the ischium enabled upright human locomotion. ${ }^{11}$ Even in man's closest relatives, the bonobos and chimpanzees, there is almost no angulation between the ischium and ilium (Figure 1). When a primate tries to stand upright, the trunk simply swings up on the femoral heads to a point that the ischium points almost directly downward. For energy-efficient human bipedal locomotion, however, lordotic angulation of the ilium relative to the ischium, increasing the lever arm of the ischio-crural muscles, was a prerequisite to be able to walk fully upright. 5,12,13 This resulted in an increase in the ischio-iliac angle and pelvic incidence during human evolution. ${ }^{5,8}$ This, in combination with the ability to fully extend the hips and knees at the same time, makes man the only species to consistently carry the body's center of gravity straight above the pelvis, rather than in front (Figure 1). This poses unique biomechanical loads on the human spine that have been shown to lead to a reduction of rotational stiffness of certain exposed segments. ${ }^{14-17}$ A previous work by Vercauteren in 1980 and Castelein et al. in 2005 has clarified that a certain area of the human spine in the upright position is posteriorly inclined, and affected by posteriorly directed shear loads. ${ }^{14,16,18}$ From this perspective, Janssen et al. showed that posterior shear loads act on all posteriorly inclined segments of the spine, as determined by each individual's sagittal profile (Figure 2). ${ }^{16,19}$ In an experimental setup, Kouwenhoven et al. showed that excessive posterior shear load results in diminished rotational stiffness of the spinal segments. ${ }^{15}$ Therefore, the more the

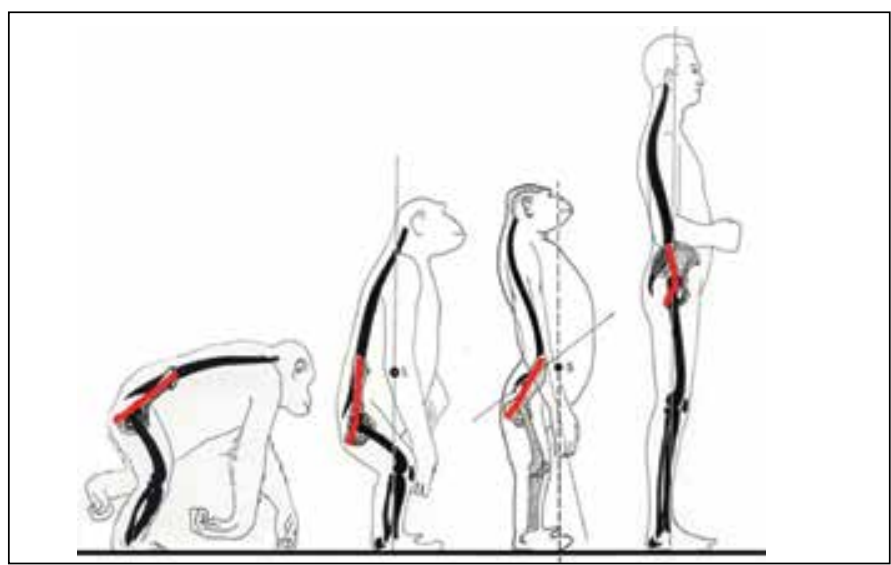

Figura 1. Hominoidae (great apes) typically display a 'bent-hip, bent-knee' posture during bipedal locomotion. Due to a backwards-bent pelvic axis (red lines), only humans are able to stand upright. ${ }^{7,8}$

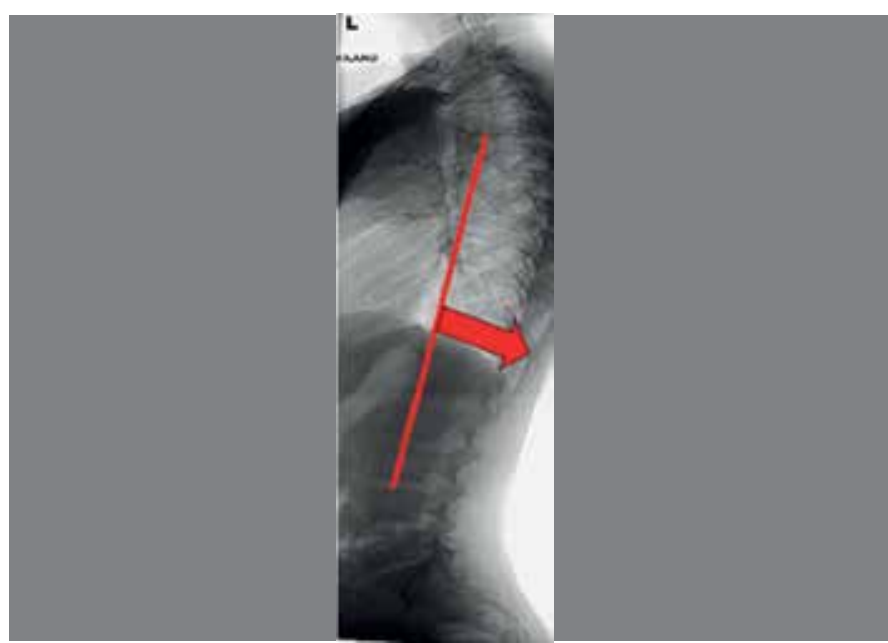

Figura 2. The sagittal spinopelvic configuration of the double-S shaped human spine in relation to the pelvis determines whether individual vertebrae are subject to either an anteriorly directed, or a posteriorly directed vector (as a vector of the axial loading). In the figure, the segments that are affected by posterior shear loading, between the apex of the thoracic kyphosis and lumbar lordosis, are shown in red.

spine exhibits areas with posteriorly tilted vertebrae, the more these segments are prone to develop a rotational deformity, in other words scoliosis. ${ }^{14,17}$ Since then, variation in sagittal alignment of the spine has been increasingly recognized in relation to the etiopathogenesis of spinal deformities. ${ }^{20-22}$

Pediatric spinal deformities have a well-known age-related preference and gender-related distribution. ${ }^{23-26}$ For example, AIS develops most frequently in girls around the time of the adolescent growth spurt. To test the hypothesis that the spine in which a rotational deformity has a chance to develop is based on differences in sagittal spinopelvic alignment, making a child prone to develop a rotational deformity, Schlösser et al. analyzed sagittal spinopelvic alignment in 156 non-scoliotic children before, during, and after the peak of pubertal growth. ${ }^{27,28}$ The results showed that thoracic kyphosis, pelvic tilt, and pelvic incidence increase during growth, and that before and during the peak of the growth spurt, a greater number of vertebrae are more posteriorly inclined as compared to after the growth spurt. Moreover, the spines of girls at the peak of the growth spurt showed more posterior inclination and a smaller thoracic kyphosis as compared to the spines of boys. This suggests that in girls around the peak of the growth spurt, the spine is subject to greater posteriorly directed shear loads, and thus shows less resistance to rotation. This may explain why AIS - under circumstances during growth that have yet to be determined - occurs more often in girls than in boys. It can also be inferred that thoracic AIS develops in a different sagittal profile as compared to (thoraco)lumbar AIS. From a multicenter database of almost 1400 AIS patients, all lateral radiographs were reviewed of children with an established, but still very small (Cobb angle smaller than 20 degrees) thoracic (Lenke 1 and $2, n=128$ ) and (thoraco) lumbar AIS (Lenke 5, $n=64$ ). A systematic analysis of the sagittal profile and exact inclination of each individual vertebra revealed that already at this very early stage, the thoracic kyphosis and posterior inclination of thoracic AIS differs significantly from (thoraco)lumbar AIS, as well as from controls. ${ }^{29-31}$ More precisely, in thoracic scoliosis, most thoracic vertebra were more backwardly inclined as compared to (thoraco) lumbar scoliosis, and vice versa. This difference in sagittal profile was shown to already exist at a very early stage of development of the rotation and the curvature, and thus can be postulated to play a role in the pathogenesis of the different curve types.

The pelvis is the key regulator of sagittal spinopelvic balance. Despite the differences in sagittal spinal alignment between thoracic and lumbar scoliosis, Mac-Thiong et al. and Farshad et al. ${ }^{31}$ were not able to demonstrate a statistically significant difference in sagittal 
pelvic anatomy between patients affected by different degrees of thoracic and (thoraco)lumbar scoliosis, using conventional radiographs. ${ }^{30,32}$ Moreover, Schlösser et al. had identical results for the parameter "pelvic incidence" in a population of Lenke type one and 5 AIS patients with curves with a Cobb angle less than 20 degrees. Recently, however, Pasha et al. introduced novel pelvic parameters based on 3-D reconstructed radiographs, and Vrtovec et al. developed a 3-D measurement method for "pelvic incidence" on 3-D CT scans, demonstrating the improved accuracy of these methods as compared to the traditional measurements on plain lateral radiographs. ${ }^{33,34}$ Using this 3-D measurement method, Brink et al. found greater pelvic incidence in a small population of thoraco(lumbar) AIS curves as compared to thoracic curves and controls. ${ }^{35}$ Therefore, their findings are consistent with previous theories, suggesting a link between sagittal pelvic anatomy, sagittal spinopelvic alignment and the development of different curve types in AIS.

\section{Why are thoracic curves predominantly right convex in adoles- cents, but left convex in infants?}

The most prevalent curve type in AIS is a right convex main thoracic curve with compensatory high-thoracic and (thoraco)lumbar curves to the left. ${ }^{36}$ In contrast to adolescent scoliosis, the main thoracic curve in infantile idiopathic scoliosis rotates and deviates far more often to the left, whereas in juvenile idiopathic scoliosis, this pattern is more evenly distributed between right and left. ${ }^{37}$

As has been known for a long time, the normal, non-scoliotic spine is also not a symmetrical structure. ${ }^{38}$ In 2006, Kouwenhoven et al. demonstrated the presence of an axial rotational pattern in the normal human spine that is similar to what is seen in the most prevalent curve patterns in idiopathic scoliosis. ${ }^{39,40}$ In 2014, we measured the rotation of each individual thoracic vertebra on CT scans in 146 asymptomatic children (the scans had been taken for reasons other than the spine such as pulmonary disease, poly-trauma, malignancy, not for the purpose of this study). Statistical analysis revealed significant differences in the rotational patterns of the spine between non-scoliotic infants, juveniles and adolescents: at the infantile age the spine was rotated to the left at all thoracic levels, at the juvenile age, the thoracic vertebrae were oriented in the midline. In contrast, at the adolescent age, the mid- and low thoracic levels (T6-T12) were significantly rotated to the right. ${ }^{41,42}$ Therefore, our analyses of non-scoliotic vertebral columns at different ages shows that transverse plane asymmetry is also a normal feature of the pediatric spine. Furthermore, the different rotational patterns between the infants, juveniles and adolescents in this study match the rotation and convexity of the curve as is normally seen in idiopathic scoliosis. The hypothesis that the convexity of the curve in idiopathic scoliosis is determined by organ distribution was recently confirmed in 2017 by Schlösser et al., who screened a unique population of primary ciliary dyskinesia patients with and without situs inversus totalis for scoliosis, retrieved 16 patients with this unique combination, and found a $94 \%$ match between organ distribution and scoliosis curve convexity. ${ }^{43}$

In contrast to the normal spine, it has long been known that the scoliotic spine is a completely asymmetrical structure. ${ }^{1}$ This was based on scoliotic specimens and experimental studies that have shown that asymmetrical growth of the neurocentral junctions of the vertebrae leads to vertebral rotation; in more detail, unilateral lag screw epiphysiodesis of the neurocentral junctions in a growing pig was shown to lead to transverse asymmetry and a rotational deformity, similar to AIS. ${ }^{44,45}$ In man however, the growth plate of the pedicles, also known as the neurocentral junctions, close before the age of eight, suggesting that any asymmetry should start before that age. ${ }^{42}$ In 2017, Brink et al. studied the transverse anatomy of the vertebrae in severe AIS in the true transverse plane, using 3-D multiplanar reconstruction of high-resolution CT scans for each individual vertebra, and reported the asymmetry of both the vertebral bodies and pedicles in a population of moderate to severe AIS patients and non-scoliotic controls. ${ }^{46}$ They observed that even in non-scoliotic controls, a certain degree of vertebral body asymmetry exists, but the asymmetry was slightly more pronounced in AIS; the concave pedicles of the thoracic primary curves were slightly $(0.4 \mathrm{~mm})$ thinner and longer $(1.8 \mathrm{~mm})$ than for the convex pedicle, especially around the apex. Interestingly, the observed asymmetry was considerably smaller than previously described. ${ }^{47-49}$ Additionally, no direct correlation was found between the degree of asymmetry, the magnitude of the Cobb angle, and the amount of rotation of the apex in these moderate to severe AIS curves. In summary, the fact there is almost no asymmetry in the true transverse plane in AIS suggests that asymmetrical growth is not the driver for rotation in AIS.

\section{What is the role of relative anterior spinal overgrowth (RASO)? \\ a. Global 3-D alignment of adolescent idiopathic scoliosis}

The Scoliosis Research Society defines scoliosis as a lateral curvature of the spine of more than 10 degrees in the coronal plane..$^{50}$ This formal definition denies the fact that it is actually a complex 3-D spinal deformity. By the late nineteenth and early twentieth centuries, using cadaver specimens, anatomists had carefully described that adolescent idiopathic scoliosis involves changes in the coronal, transverse, as well as the sagittal planes: in the coronal plane, it is characterized by lateral deviation and lateral bending, in the transverse plane by axial rotation, asymmetrical growth of the pedicles and asymmetrical closure of the neurocentral cartilages, and in the sagittal plane by lordosis of the apical segments and hypertrophy of the facet joints. ${ }^{1,51,52} \mathrm{~A}$ typical feature of the curves in AIS is the coupling between the phenomena in the three different planes. In 1952, Somerville and Roaf described that during the development of AIS, the vertebral bodies rotate away from the midline toward the convexity, to a more lateral position than the posterior elements of the spine. ${ }^{44,53}$ By definition, axial rotation towards the convexity of the curve leads to a spinal column that is latero-flexed and is longer anteriorly than posteriorly, in other words, rotated lordosis of the apex. With the advent of radiography, unfortunately scoliosis gradually became regarded as a coronal plane deformity, until a number of authors re-emphasized the importance of the sagittal plane. ${ }^{44,53-56}$ Because of the rotated apical lordoses in AIS, Stagnara introduced le plan d'election, a rotated view to evaluate the true coronal profile of the apical segments of the curvature. ${ }^{57}$ Using its equivalent in the sagittal plane, in 1984 Dickson et al. observed in 70 AIS patients that instead of a normal thoracic kyphosis, $75 \%$ of AIS curves were lordotic, $24 \%$ were straight, and only $1 \%$ were kyphotic. . $^{54,55}$ Ultimately, this has led to the assumption that idiopathic scoliosis may be a problem of generalized anterior overgrowth of the whole spine, or a discrepancy of growth of the spinal cord as compared to growth of the vertebrae. ${ }^{58-62}$

Although the 3-D aspect of AIS has been studied for over a century and has been given much attention in recent years in the literature, the true 3-D morphology, and especially the sagittal deformation, of the different areas of the scoliotic spine, has only recently been described in detail. This overview summarizes the findings of recent 3-D studies on a unique dataset of AIS cases that had undergone high-resolution computed tomographic imaging of the spine preoperatively for navigation purposes. The scans were analyzed using special software to generate complete 3-D reconstructions and describe the 3-D deformation of different regions of the spine in AIS patients in the coronal, transverse and true sagittal planes in great detail (Figure 3). Interestingly, quantitative description of the 3-D morphology of AIS revealed that (1) the global 3-D development of AIS curves follows a rather uniform pattern with coupling of the different aspects of the deformity in all three planes and that (2) all AIS curves, structural as well as nonstructural, primary as well as compensatory, thoracic as well as (thoraco)lumbar, were characterized by greater anterior length (on average $4.1 \%$ ) measured from Cobb end vertebra to Cobb end vertebra (Figure 4). ${ }^{63}$ The junctional segments between the curves were more or less straight.

This so-called relative anterior spinal anterior overgrowth, or non-synchronous anterior-posterior growth, has been considered as part of the etiologic mechanism of idiopathic scoliosis. ${ }^{1,53,55,63,64}$ However, our recent research has shown that neuromuscular scoliosis demonstrates the same pattern of relative anterior spinal overgrowth as idiopathic scoliosis. ${ }^{65}$ This suggests that anterior lengthening of the spine is part of a more generalized mechanism that is the consequence of the curvature, not its cause. 


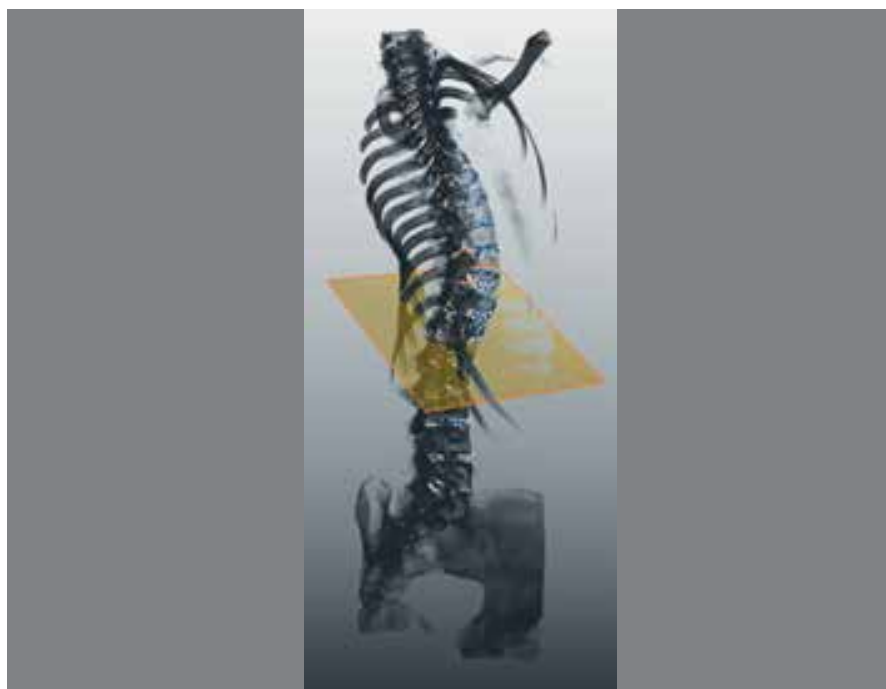

Figura 3. A posterolateral view that represents a true lateral view of the apical thoracic region of a complete 3-D reconstruction of an adolescent idiopathic scoliosis patient demonstrating that the thoracic curvature is a rotated lordosis.

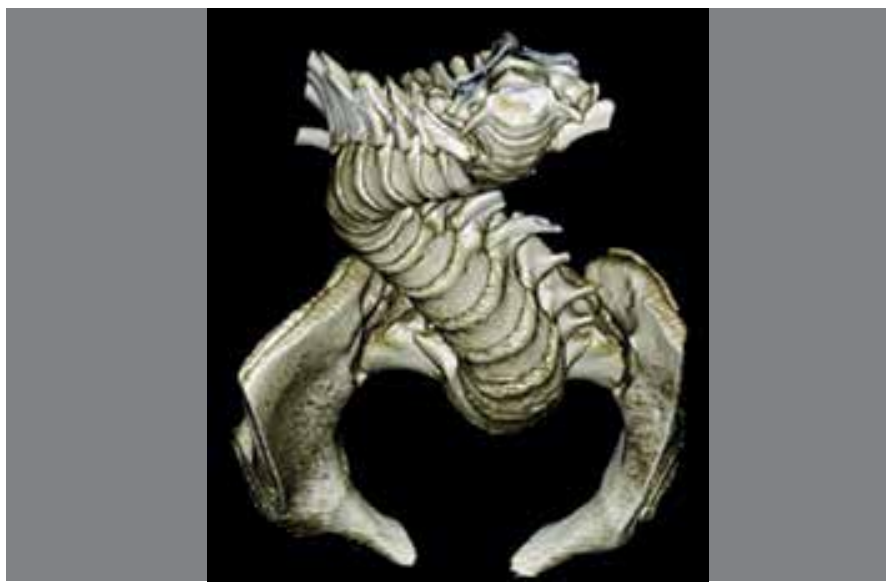

Figura 4. A craniocaudal view on a 3-D reconstruction of the spinopelvic complex of an adolescent idiopathic scoliosis patient demonstrating the complex rotational pattern of the rotated apical segments.

\section{b. Segmental 3-D morphology of adolescent idiopathic scoliosis}

There is an ongoing debate on the development of the excess of anterior spinal length in AIS. In two-dimensional radiographic studies on AIS, contradictory findings have been reported on the individual contribution of the vertebral bodies, as compared to the discs, to the coronal deformity. ${ }^{66-75}$ Because the spinal column in AIS, unlike the normal situation, is longer anteriorly than posteriorly, it has been hypothesized that AIS is the result of active anterior overgrowth of the vertebral bodies, or reduced posterior growth by posterior tethering. ${ }^{60,61}$ Furthermore, disorders of bone metabolism have been suggested to play an etiological role. From our etiological perspective, however, the anterior-posterior length discrepancy in AIS is secondary to axial rotation. Therefore, we addressed the important question of which anatomical structure and which plane give rise to the deformity in AIS. We used the same series of high-resolution CT-scans and software as those used for the study presented above, to investigate, at the segmental level whether the 3-D deformation of the spine in AIS is predominantly localized in the vertebral bodies (as a result of active growth) or in the discs (as a secondary phenomenon to axial rotation). Segmental parameters were determined for each individual disc (total $\mathrm{n}=924$ ) and vertebra (total $\mathrm{n}=1078$ ) between T4 and L5. Interestingly, in contrast to previous studies, in scoliosis the intervertebral discs were at least three times more deformed in the coronal, true transverse and true sagittal planes than in the vertebral bodies ${ }^{71,73}$ Anterior-posterior and coronal wedging was more pronounced at the apices of the curves, whereas mechanical torsion was found in all regions of the spine. Most of the excess anterior length in the scoliotic thoracic spine, both in idiopathic as well as in neuromuscular cases, appeared to be caused by a substantial difference in height of the anterior portion of the disc compared to its posterior aspect, whereas the vertebral bodies showed almost no relative anterior overgrowth compared to normal children. ${ }^{65,76}$ The conclusions of this and the previous study are that excess of anterior length is not a global, but rather a regional phenomenon, and that since the deformity is much more in the disc than in the bone, it seems more of a passive phenomenon than an active growth process. The anterior wedging of the discs could be a mechanical effect caused by unloading of the anterior spine by its position rotated away from the midline in both types of scoliosis.

\section{CONCLUSIONS}

In this overview, evidence from multiple cross-sectional imaging studies is provided that supports the hypothesis that rotational stiffness of the human spine in general is less than in all other species, due to the existence of destabilizing posteriorly directed shear load that are the result of the unique spinopelvic alignment of the human spine. Under certain, as yet ill-defined, circumstances, the delicate balance that normally exists between these rotation-inducing forces, and the body's compensating mechanisms, can be disturbed during the vulnerable period of the growth spurt. We showed that, amongst many other things, spinopelvic alignment also changes rapidly during puberty, and in a different manner between boys and girls. This may lead to the rotatory decompensation that we call scoliosis. Our studies have also demonstrated that once the spine decompensates into this rotational deformity, it will follow the pre-existent rotational pattern that also exists in the normal, non-scoliotic spine. This process of rotation away from the midline, in which the posterior structures stay behind, ultimately leads to the development of a rotated, apical lordosis. This lordosis, or excess anterior length, takes place predominantly in the soft tissues and not in the bone; there is no evidence of an actual disturbance of bony growth, rather, the discs expand in their anterior aspects and the interlaminar and interspinous soft tissues are compressed posteriorly with the facet joints as a fulcrum, so that the process resembles passive extension of the normal spine. We can conclude that AIS has an intrinsic biomechanical basis: an imbalance between the biomechanical loading of the upright human spine (i.e. posteriorly directed shear loading) on the one hand and the body's compensating mechanisms on the other.

The question remains: "What underlying mechanisms and structures influence rotational stability of the spine and predispose the spines of otherwise healthy children to decompensate into a rotational deformity, while the spines of other children remain unaffected?" In one of our studies, we found that the geometry of the intervertebral disc is most affected in AIS as compared to the vertebral bodies. Moreover, this structure may play a key role in the rotational stability of the pediatric and adult spine. From our perspective, as a first step to answering this question, factors that influence the rotational stability of the intervertebral discs should be elucidated. This is, at present, the focus of our continuing studies.

All authors declare no potential conflict of interest related to this article.

CONTRIBUTION OF THE AUTHORS: This non-systematic review article has three authors. Each author made significant individual contributions to this manuscript. TS and RB were the main contributors in the drafting of the manuscript. RC performed the review of the manuscript and was the main contributor to the intellectual concept of the described etiological hypothesis. 


\section{REFERENCES}

1. Nicoladoni C. Anatomie und Mechanismus der Skoliose. In: Kocher, König, von Mikulicz, eds. Bibliotheca medica, Stuttgart: Verlag von Erwin Nagele, 1904.

2. Kouwenhoven JW, Castelein RM. The pathogenesis of adolescent idiopathic scoliosis: review of the literature. Spine (phila Pa 1976). 2008;33(26):2898-908.

3. SchlösserTP, van der Heijden GJ, Versteeg AL, Castelein RM. How idiopathic is adolescent idiopathic scoliosis? A systematic review on associated abnormalities. PLoS One. 2014;9(5):e97461.

4. Janssen MM, de Wilde RF, Kouwenhoven JW, Castelein RM. Experimental animal models in scoliosis research: a review of the literature. Spine J. 2011:11(4):347-58.

5. Washburn SL. The analysis of primate evolution with particular reference to the origin of man. Cold Spring Harb Symp Quant Biol.1950;15:67-78.

6. Kummer B. Biomechanical problems of upright posture. Ann Anat. 1992;174(1):33-9

7. Schlösser TP, Janssen MM, Vrtovec T, Pernuš F, Oner FC, Viergever MA, et al. Evolution of the ischio-iliac lordosis during natural growth and its relation with the pelvic incidence. Eur Spine J. 2014;23(7):1433-41.

8. Schlösser TP, Janssen MM, Hogervorst T, Vrtovec T, de Vos J, Öner FC, et al. The odyssey of sagittal pelvic morphology during human evolution: a perspective on different hominoidae. Spine J. 2017:17(8):1202-6.

9. Foster AD, Raichlen DA, Pontzer H. Muscle force production during bent-knee, bent-hip walking in humans. J Hum Evol. 2013;65(3):294-302.

10. Lovejoy CO. The natural history of human gait and posture. Part 1. Spine and pelvis. Gait Posture. 2005:21(1):95-112

11. RakY. Lucy's pelvic anatomy: its role in bipedal gait. J Hum Evol. 1991;20:283-90.

12. Whitcome KK, Shapiro LJ, Lieberman DE. Fetal load and the evolution of lumbar lordosis in bipedal hominins. Nature. 2007;450(7):1075-8

13. Tardieu C, Bonneau N, Hecquet J, Boulay C, Marty C, Legaye J, et al. How is sagitta balance acquired during bipedal gait acquisition? Comparison of neonatal and adult pelves in three dimensions. evolutionary implications. J Hum Evol. 2013:65(2):209-222.

14. Castelein RM, van Dieen JH, SmitTH. The role of dorsal shear forces in the pathogenesis of adolescent idiopathic scoliosis--a hypothesis. Med Hypotheses. 2005;65(3):501-508.

15. Kouwenhoven JW, SmitTH, van der Veen AJ, Kingma I, van Dieën JH, Castelein RM. Effects of dorsal versus ventral shear loads on the rotational stability of the thoracic spine: a biomechanical porcine and human cadaveric study. Spine (Phila Pa 1976). 2007;32:(23)2545-50.

16. Janssen MM, Drevelle X, Humbert L, Skalli W, Castelein RM. Differences in male and female spino-pelvic alignment in asymptomatic young adults: $A$ three-dimensional analysis using upright low-dose digital biplanar X-rays. Spine (Phila Pa 1976). 2009:34(23):E826-32.

17. Janssen MM, Kouwenhoven JW, Castelein RM. The role of posteriorly directed shear loads acting on a pre-rotated growing spine: a hypothesis on the pathogenesis of idiopathic scoliosis. Stud Health Technol Inform. 2010;158:112-117.

18. Vercauteren M. Dorso-Lumbale curvendistributie en etiopathogenie van de scoliosis adolescentium. [Thesis]. Ghent: Ghent University, 1980.

19. Janssen MM, Vincken KL, van Raak SM, Vrtovec T, Kemp B, Viergever MA, et al. Sagittal spinal profile and spinopelvic balance in parents of scoliotic children. Spine J. 2013;13(12):1789-800

20. Vialle R, Ilharreborde B, Dauzac C, Lenoir T, Rillardon L, Guigui P. Is there a sagittal imbalance of the spine in isthmic spondylolisthesis? A correlation study. Eur Spine J. 2007:16(10):1641-9.

21. Vialle R, Levassor N, Rillardon L, Templier A, Skalli W, Guigui P. Radiographic analysis of the sagittal alignment and balance of the spine in asymptomatic subjects. J Bone Joint Surg Am. 2005;87(2):260-7.

22. Roussouly P, Gollogly S, Berthonnaud E, Labelle H, Weidenbaum M. Sagittal alignment of the spine and pelvis in the presence of L5-s1 isthmic lysis and low-grade spondylolisthesis. Spine (Phila Pa 1976). 2006;31(21):2484-90.

23. Scheuermann H. Kyphosis dorsalis juvenilis. Z Orthop Chir. 1921;41:305-17.

24. Wynne-Davies R. Familial (idiopathic) scoliosis. A family survey. J Bone Joint Surg Br. 1968:50(1):24-30

25. Dickson RA. The aetiology of spinal deformities. Lancet. 1988;1(8595):1151-5.

26. Altaf F, Gibson A, Dannawi Z, Noordeen H. Adolescent idiopathic scoliosis. BMJ. 2013;346:f2508

27. Dimeglio A. Growth in pediatric orthopaedics. J Pediatr Orthop. 2001;21(4):549-55.

28. Risser JC. The iliac apophysis: an invaluable sign in the management of scoliosis. Clin Orthop. 1958;11:111-9.

29. Grivas TB, Dangas S, Samelis P, Maziotou C, Kandris K. Lateral spinal profile in school-screening referrals with and without late onset idiopathic scoliosis 10 degrees-20 degrees. Stud Health Technol Inform. 2002:91:25-31.

30. Mac-Thiong JM, Labelle H, Charlebois M, Huot MP, de Guise JA. Sagittal plane analysis of the spine and pelvis in adolescent idiopathic scoliosis according to the coronal curve type. Spine (Phila Pa 1976). 2003;28(13):1404-9

31. Upasani VV, Tis J, Bastrom T, Pawelek J, Marks M, Lonner B, et al. Analysis of sagittal alignment in thoracic and thoracolumbar curves in adolescent idiopathic scoliosis: how do these two curve types differ? Spine (Phila Pa 1976). 2007:32(12):1355-9

32. Tari SHV, Mahabadi EA, Ghandehari H, Nikouei F, Javaheri R, Safdari F. Spinopelvic sagittal alignment in patients with adolescent idiopathic scoliosis. Shafa Ortho J. 2015;2(3):e739.

33. Vrtovec T, Janssen MM, Likar B, Castelein RM, Viergever MA, Pernus F. A review of methods for evaluating the quantitative parameters of sagittal pelvic alignment. Spine J. 2012;12(5):433-46

34. Pasha S, Aubin CE, Sangole AP, Labelle H, Parent S, Mac-Thiong JM. Three-dimensional spinopelvic relative alignment in adolescent idiopathic scoliosis. Spine (Phila Pa 1976). 2014;39(7):564-70

35. Brink RC, Vavruch L, Schlösser TP, et al. Three-dimensional pelvic incidence is much higher in (thoraco) lumbar scoliosis than in thoracic scoliosis and controls. peer-reviewed abstract P. Zorab Symposium, British Scoliosis Research Foundation. UK. 2017.

36. Lenke LG, Betz RR, Harms J, Bridwell KH, Clements DH, Lowe TG, et al. Adolescent idiopathic scoliosis: a new classification to determine extent of spinal arthrodesis. J Bone Joint Surg Am. 2001:83-A(8):1169-81.

37. Wynne-Davies R. Infantile idiopathic scoliosis. Causative factors, particularly in the first six months of life. J Bone Joint Surg Br. 1975;57:138-41.

38. Kouwenhoven JW, Bartels LW, Vincken KL, Viergever MA, Verbout AJ, Delhaas T, et al. The relation between organ anatomy and pre-existent vertebral rotation in the normal spine: magnetic resonance imaging study in humans with situs inversus totalis. Spine (Phila Pa 1976). 2007:32(10):1123-8

39. Kouwenhoven JW, Vincken KL, Bartels LW, Castelein RM. Analysis of preexistent vertebral rotation in the normal spine. Spine (Phila Pa 1976). 2006; 31(13):1467-72.
40. Janssen MM, Vincken KL, Kemp B, Obradov M, de Kleuver M, Viergever MA, et al. Pre-existent vertebral rotation in the human spine is influenced by body position. Eur Spine J. 2010;19(10):1728-34

41. Janssen MM, Kouwenhoven JW, Schlösser TP, Viergever MA, Bartels LW, Castelein RM, et al. Analysis of preexistent vertebral rotation in the normal infantile, juvenile, and adolescent spine. Spine (Phila Pa 1976). 2011:36(7):E486-91.

42. Schlösser TP, Janssen MM, Attrach $H$, Viergever MA, Vincken KL, Castelein RM. Systematic analysis of the neurocentral junction (NCJ) in the normal infantile, juvenile and adolescent spine; research into spinal deformities. Stud Health Technol Inform. 2012;176:482

43. Schlösser TP, Semple T, Carr SB, Padley S, Loebinger MR, Hogg C, et al. Scoliosis convexity and organ anatomy are related. Eur Spine J. 2017;26(6):1595-99.

44. Roaf R. The basic anatomy of scoliosis. J Bone Joint Surg Br. 1966;48(4):786-92.

45. Taylor JR. Scoliosis and growt: patterns of asymmetry in normal vertebral growth. Acta Orthop Scand. 1983;54(4):596-602.

46. Brink RC, Schlösser TP, Colo D, Vincken KL, van Stralen M, Hui SC, et al. Asymmetry of the vertebral body and pedicles in the true transverse plane in adolescent idiopathic scoliosis: a CT-based study. Spine Deform. 2017;5(1):37-45

47. Liljenqvist UR, Allkemper T, Hackenberg L, Link TM, Steinbeck J, Halm HF. Analysis of vertebral morphology in idiopathic scoliosis with use of magnetic resonance imaging and multiplanar reconstruction. J Bone Joint Surg Am. 2002:84-A(3):359-68.

48. Takeshita K, Maruyama T, Chikuda H, Shoda N, Seichi A, Ono T, et al. Diameter, length, and direction of pedicle screws for scoliotic spine: analysis by multiplanar reconstruction of computed tomography. Spine (Phila Pa 1976). 2009;34(8):798-803.

49. Abul-Kasim K, Ohlin A. Patients with adolescent idiopathic scoliosis of lenke type-1 curve exhibit specific pedicle width pattern. Eur Spine J. 2012:21(1):57-63.

50. Scoliosis Research Society terminology committee and working group on spinal classification revised glossary of terms [homepage on the Internet]. 2000. Available from: http://www.srs.org/professionals/glossary/SRS_revised_glossary_of_terms.htm

51. Adams W. Lectures on the pathology and treatment of lateral and other forms of curvature of the spine. 2nd ed. London: J \& A Churchill, 1882

52. Meyer GH. Die mechanik der skoliose. Archiv für pathologische Anatomie und Physiologie und für klinische Medicin. 1866;35(2):225-253

53. Somerville EW. Rotational lordosis; the development of single curve. J Bone Joint Surg Br. 1952;34-B(3):421-7.

54. Deacon $\mathrm{P}$, Flood BM, Dickson RA. Idiopathic scoliosis in three dimensions. A radiographic and morphometric analysis. J Bone Joint Surg Br. 1984;66(4):509-12

55. Dickson RA, Lawton JO, Archer IA, Butt WP. The pathogenesis of idiopathic scoliosis biplanar spinal asymmetry. J Bone Joint Surg Br. 1984;66(1):8-15.

56. Archer IA Dickson RA. Stature and idiopathic scoliosis. A prospective study. J Bone Joint Surg Br. 1985;67(2):185-8.

57. Stagnara P, De Mauroy JC, Dran G, Gonon GP, Costanzo G, Dimnet J, et al. Reciproca angulation of vertebral bodies in a sagittal plane: approach to references for the evaluation of kyphosis and lordosis. Spine. (Phila Pa 1976). 1982;7(4):335-42.

58. Chu WC, Lam W, Ng BK, Tze-Ping L, Lee KM, Guo X, et al. Relative shortening and functional tethering of spinal cord in adolescent scoliosis - Result of asynchronous neuro-osseous growth, summary of an electronic focus group debate of the IBSE. Scoliosis. 2008:3:8.

59. Guo X, Chau WW, Chan YL, Cheng JC, Burwell RG, Dangerfield PH. Relative anterior spinal overgrowth in adolescent idiopathic scoliosis-result of disproportionate endochondral-membranous bone growth? Summary of an electronic focus group debate of the IBSE. Eur Spine J. 2005;14(9):862-73.

60. Guo X, Chau WW, Chan YL, Cheng JC. Relative anterior spinal overgrowth in adolescent idiopathic scoliosis: results of disproportionate endochondral-membranous bone growth J Bone Joint Surg Br. 2003:85(7):1026-31.

61. Porter RW. Can a short spinal cord produce scoliosis? Eur Spine J. 2001;10:2-9.

62. Porter RW. Idiopathic scoliosis: the relation between the vertebral canal and the vertebra bodies. Spine (Phila Pa 1976). 2000;25(11):1360-6.

63. Schlösser TP, van Stralen M, Chu WC, Lam TP, Ng BK, Vincken KL, et al. Anterior over growth in primary curves, compensatory curves and junctional segments in adolescent idiopathic scoliosis. PLoS One. 2016;11(7):e0160267.

64. ChuWC, Lam WW, Chan YL, Ng BK, Lam TP, Lee KM, et al. Relative shortening and functional tethering of spinal cord in adolescent idiopathic scoliosis? study with multiplanar reformat magnetic resonance imaging and somatosensory evoked potential. Spine (Phila Pa 1976). 2006;31(1):E19-25.

65. Brink RC, Schlösser TPC, Colo D, Vavruch L, van Stralen M, Vincken KL, et al. Anterior spinal overgrowth is the result of the scoliotic mechanism and is located in the disc. Spine (Phila Pa 1976). 2017;42(11):818-22.

66. Parent S, Labelle H, Skalli W, de Guise J. Vertebral wedging characteristic changes in scoliotic spines. Spine (Phila Pa 1976). 2004:29(20):E455-62

67. Perdriolle R, Boffelli N, Ousset M. La scoliose: son étude tridimensionnelle. Paris: Maloine, 1979

68. Perdriolle R, Becchetti S, Vidal J, Lopez P. Mechanical process and growth cartilages: essential factors in the progression of scoliosis. Spine (Phila Pa 1976). 1993;18:343-9.

69. Xiong B, Sevastik JA, Hedlund R, Sevastik B. Radiographic changes at the coronal plane in early scoliosis. Spine (Phila Pa 1976). 1994:19(2):159-64.

70. Ronchetti PJ, Stokes IA, Aronsson DD. Vertebral body and disc wedging in scoliosis. In: Sevastik JA, Diab KM, eds. Research into spinal deformities 1. Amsterdam: IOS Press, 1997:81-84

71. Stokes IA, Aronsson DD. Disc and vertebral wedging in patients with progressive scoliosis. J Spinal Disord. 2001:14(4):317-22.

72. Stokes $\mid A$, Windisch $L$. Vertebral height growth predominates over intervertebral disc height growth in adolescents with scoliosis. Spine (Phila Pa 1976). 2006;31(14):1600-4.

73. Modi HN, Suh SW, Song HR, Yang JH, Kim HJ, Modi CH. Differential wedging of vertebral body and intervertebral disc in thoracic and lumbar spine in adolescent idiopathic scoliosis: a cross sectional study in 150 patients. Scoliosis. 2008:3:11.

74. Will RE, Stokes IA, Qiu X, Walker MR, Sanders JO. Cobb angle progression in adolescent scoliosis begins at the intervertebral disc. Spine (Phila Pa 1976). 2009;34(25):2782-6.

75. Xu HG, Qiu GX, Wang YP, Zhang JG, Liu Y, Wu ZH. Imaging study of wedge changes in the vertebral bodies and intervertebral discs in adolescent idiopathic scoliosis. Orthop Surg 2009:1(4):300-4

76. Schlösser TP, van Stralen M, Brink RC, Chu WC, Lam TP, Vincken KL, et al. Three-dimensional characterization of torsion and asymmetry of the intervertebral discs versus vertebra bodies in adolescent idiopathic scoliosis. Spine (Phila Pa 1976). 2014;39(19):E1159-66. 